\title{
EMERGING EVIDENCE REGARDING THE ROLES OF EMOTIONAL, BEHAVIOURAL, AND COGNITIVE ASPECTS OF STUDENT ENGAGEMENT IN THE ONLINE CLASSROOM
}

\author{
Alexandra Pentaraki [alexandra.pentaraki@online.liverpool.ac.uk], University of Liverpool/Laureate \\ Education [https:// wnw.university-liverpool-online.com/programmes/psychology], United Kingdom, Gary J. \\ Burkholder[gary.burkholder@laureate.net,gary.burkholder@waldenu.ed],Walden University,Minneapolis, \\ MN, USA / Laureate Education, Inc., United States of America
}

\begin{abstract}
There is emerging evidence that suggests emotions as a discrete factor in academic online contexts that significantly contribute to student engagement and higher order learning (Cleveland-Innes \& Campbell, 2012; You, 2012, You \& Kang, 2014; Zembylas, 2008; Liaw, 2008). Pekrun (2000) and Pekrun, Goetz, Frenzel, Barchfeld, and Perry (2011) developed the control-value theory of achievement emotion that not only showed that emotions represent a discrete category in student engagement, but that there are certain factors such as perceived academic control and self-regulation that function as antecedents of students' emotional reactions that affect online learning. The aim of the present paper is to review the emerging research evidence of the impact of emotions on students' engagement in order to understand the distinct role that emotions may play in online learning. The review also proposes strategies and activities that teachers can use in order to enhance students' positive engagement in online learning. The findings suggest that emotions are significant factors in students' engagement in online learning while cognitive and behavioural factors function as antecedents of emotions in online contexts. The inclusion of emotional, cognitive and behavioural strategies in online teaching can enhance students' engagement and learning experience in the online classroom.
\end{abstract}

\section{Abstract in Greece}

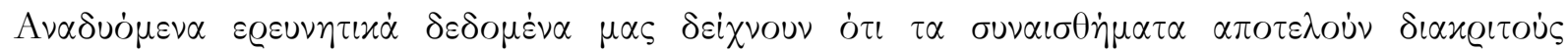

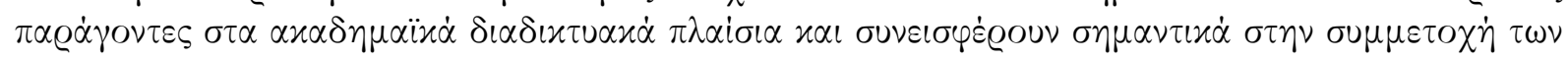

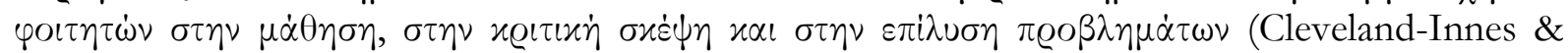
Campbell, 2012; You, 2012, You \& Kang, 2014; Zembylas, 2008; Liaw, 2008). O Pekrun (2000)

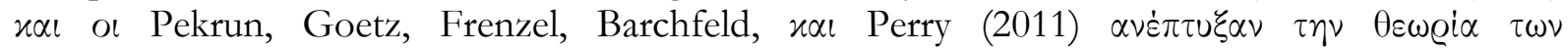

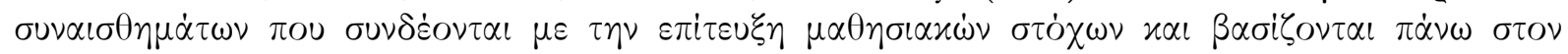

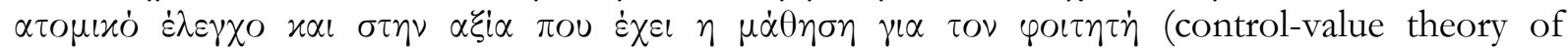

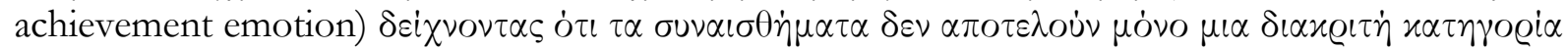

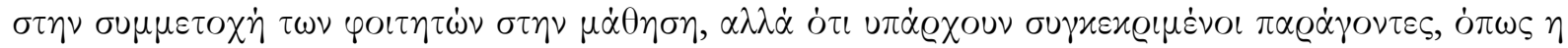

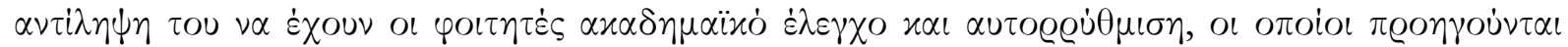

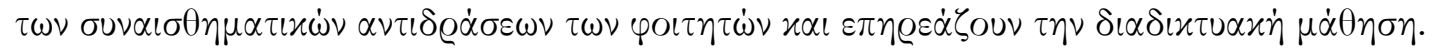

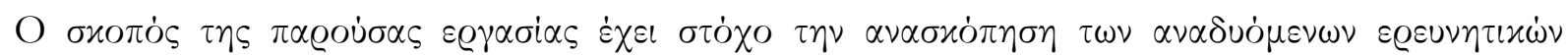

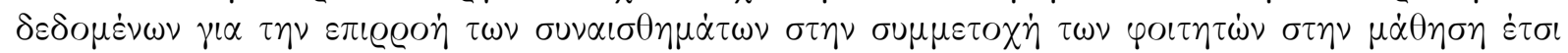

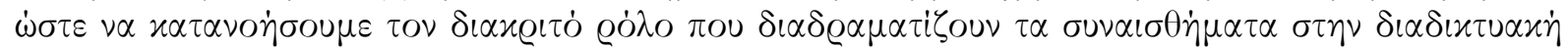

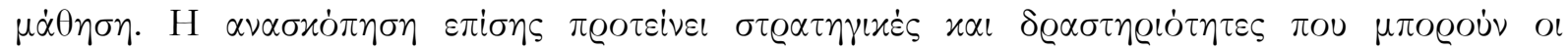

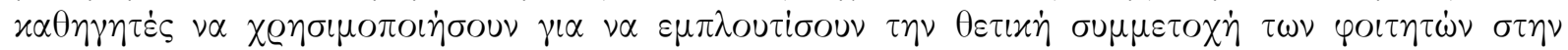

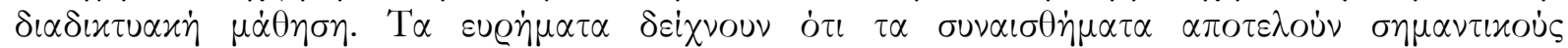

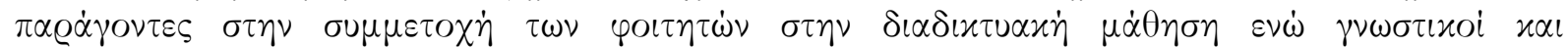




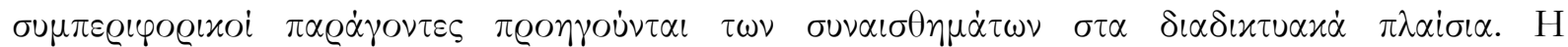

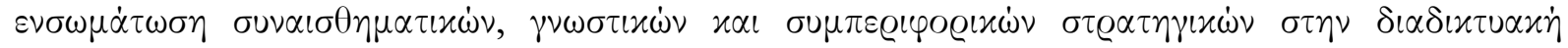

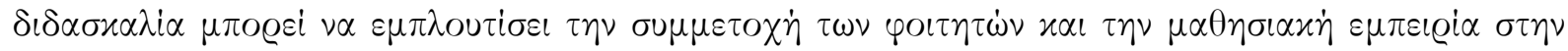
$\delta\llcorner\alpha \delta \iota \tau u \alpha x \dot{\eta} \tau \dot{\alpha} \xi \eta$

\section{Abstract in Spanish}

Existe evidencia emergente que sugiere que las emociones son un factor discreto en los contextos académicos en línea que contribuyen significativamente a la participación de los estudiantes y al aprendizaje de orden superior (Cleveland-Innes \& Campbell, 2012; You, 2012, You \& Kang, 2014; Zembylas, 2008; Liaw, 2008). Pekrun (2000) y Pekrun, Goetz, Frenzel, Barchfeld, y Perry (2011) desarrollaron la teoría del control-valor de las emociones de logro que no sólo demuestra que las emociones representan una categoría discreta en la participación estudiantil, sino que hay ciertos factores, como el control académico percibido y la autorregulación, que funcionan como antecedentes a las reacciones emocionales de los estudiantes que afectan el aprendizaje en línea. El objetivo de este artículo es revisar la evidencia emergente de investigaciones sobre impacto de las emociones en la participación de los estudiantes para comprender el papel específico que las emociones pueden jugar en el aprendizaje en línea. La revisión también propone estrategias y actividades que los profesores pueden utilizar para mejorar la participación positiva de los estudiantes en el aprendizaje en línea. Los hallazgos sugieren que las emociones son factores significativos en la participación de los estudiantes en el aprendizaje en línea, mientras que los factores cognitivos y de comportamiento funcionan como antecedentes de las emociones en los contextos en línea. La inclusión de estrategias emocionales, cognitivas y conductuales en la enseñanza en línea puede mejorar la participación de los estudiantes y la experiencia de aprendizaje en el aula en línea.

\section{Abstract in Portuguese}

Há evidências emergentes que sugerem que as emoções são um fator discreto nos contextos acadêmicos online que contribuem significativamente para o engajamento dos alunos e a aprendizagem de ordem superior (Cleveland-Innes \& Campbell, 2012; You, 2012, You \& Kang, 2014; Zembylas, 2008; Liaw, 2008). Pekrun (2000) e Pekrun, Goetz, Frenzel, Barchfeld, e Perry (2011) desenvolveram a teoria do controle-valor das emoções de realização que, não só mostrou que as emoções representam uma categoria discreta no engajamento do aluno, mas que existem certos fatores como a percepção de controle acadêmico e auto-regulação que funcionam como antecedentes das reações emocionais dos alunos que afetam a aprendizagem online. O objetivo deste artigo é revisar a evidência emergente nas pesquisas sobre o impacto das emoções no engajamento de estudantes para compreender o papel específico que as emoções podem jogar na aprendizagem online. A revisão também propõe estratégias e atividades que os professores podem usar para melhorar o envolvimento positivo dos estudantes na aprendizagem online. Os resultados sugerem que as emoções são fatores significativos no engajamento dos estudantes na aprendizagem online, enquanto que os fatores cognitivos e comportamentais funcionam como antecedentes das emoções em contextos online. A inclusão de estratégias emocionais, cognitivas, e comportamentais no ensino online pode melhorar o envolvimento dos estudantes e a experiência de aprendizagem na sala de aula online.

Keywords: online learning, emotions, cognition, behaviour, student engagement, higher education 


\section{Introduction}

A number of theoretical advances have emerged as our understanding of the factors important to online learning has increased. One of the most influential theoretical frameworks, the community of inquiry model (COI) (Garrison, Anderson, \& Archer, 2000), identifies social, cognitive, and teaching presence as fundamental to the online learning experience and important for collaborative and higher order learning. Social presence reflects the ability of learners to express themselves socially and emotionally in order to be perceived as 'real people' in the online environment. Cognitive presence involves the degree that learners are able to construct and confirm meaning on the basis of discourse and reflection. Teaching presence refers to instructional design, teachers' facilitation, and direction of social and cognitive presence that will help the learner achieve a personally meaningful learning outcome.

The COI model does not consider emotional presence as a discrete factor in student engagement and learning. Instead, the model conceptualizes emotional presence as overlapping with social presence (Garrison, Anderson, \& Archer, 2010). Although research has supported the theoretical constructs of the COI model, there is still a debate about its explanatory power related to online learning (Garrison \& Arbaugh, 2007). The lack of quantitative studies, the use of different statistical methods in the few quantitative studies that have been conducted, and the focus on qualitative studies that examine transcripts, texts, and coding protocols may account for the lack of consistent findings. Failure also to conceptualize emotional presence as a discrete construct in explanatory models of online learning, including the COI model, may lead to misinterpretation of the potential effect of emotional presence on student learning. While the COI model considers socio-emotional communication to be important, it does not consider its effect on learning. Emotion and social interactions cannot be studied separately from cognitive and teaching presence (Garrison \& Arbaugh, 2007).

Student engagement involves cognitive, behavioural, and emotional dimensions that contribute to higher-order thinking and motivate students' learning (Trowler, 2010). The main components of student engagement, on the basis of Bloom's taxonomy, have been conceptualized using three dimensions of engagement - behavioural, emotional, and cognitive. Behavioural engagement refers to student attendance and involvement in a course and includes negative behaviours, such as classroom misbehaviour (e.g., a student is posting aggressive comments or is rude towards his/her classmates). Emotional engagement involves affective reactions such as interest, sense of belonging, enjoyment, boredom, rejection, and frustration, while cognitive engagement reflects interest in learning by going beyond class requirements or even redefining the parameters of assignments.

Cognitive, behavioural, and emotional dimensions of student engagement involve feelings, sense making, and action. Consequently, a dimensional model of engagement would assert that acting without any feeling reflects just involvement or compliance in learning (Fredricks, Blumenfeld, \& Paris, 2004). Although the COI model posits that socio-emotional communication establishing social presence in the online classroom is important for student engagement, it does not consider socio-emotional communication as a dynamic dimension of online learning. In short, the COI model focuses solely on the educational purpose of establishing teaching, social, and cognitive presence and asserts that personal relationships and interactions, which have emotional components, must be defined in strict academic terms (Garrison \& Arbaugh, 2007). This appears counter to existing literature that shows the importance of emotional involvement on student engagement and learning in online contexts (Pekrun, Goetz, Daniels, Stupnisky, \& Perry, 2010). 
Nevertheless, we believe that it is important to clarify some misconceptions that seem to characterize the field and that these need to be taken into consideration in the design of future studies on emotions and online learning. Overall, it is essential to distinguish the study of emotion as a distinct factor in online learning (e.g., helping students or not helping them to increase higher order thinking) from the study of emotion as increasing student engagement with online learning. Emerging evidence, as this review suggests, shows that emotions may have a mediating effect on online learning via their significant impact that emotions appear to have on engagement with their online learning; that is, emotional states and related factors seem to influence the way students will engage with their online learning and performance.

The aim of this paper is to review the emerging research evidence of the impact of emotions on online learning specifically as it relates to student engagement in order to understand the distinct role that emotion may play in online learning. The relationship of emotion to cognitive and behavioural aspects of learning as well as student individual differences will be also reviewed, as there is evidence that supports the effect of emotion, cognition, behaviour, and individual differences on student engagement and higher order thinking in online learning. On the basis of this review certain emotional, cognitive and behavioural strategies and activities will be discussed with the goal of assisting teachers with improving student engagement in the online classroom.

\section{The impact of emotion on student engagement and higher order thinking in online learning}

Although the impact of emotions on learning has not been examined widely in both traditional and online learning environments, emerging evidence suggests the discrete role emotional involvement plays in learning. Pekrun, Goetz, Titz, and Perry (2002) and Pekrun et al. (2010) showed that emotions, defined as academic emotions which include, hope, pride, relief, anxiety, anger, shame, boredom, and hopelessness, were significantly related to academic achievement, student motivation, learning strategies, self-regulation, and value appraisals.

Cleveland-Innes and Campbell (2012) showed that emotional expressions were not only significant indicators of social presence in the online classroom but that emotions emerge as a distinct factor in the online classroom. The authors defined emotional presence as "the outward expression of emotion, affect, and feeling by individuals and among individuals in a community of inquiry, as they relate to and interact with the learning technology, course content, students, and the instructor" (p.283). The researchers showed that emotions, reflected in the classroom as exhibiting appreciation, delight, disappointment, fear, frustration, hope, and preference, were present when students referred to their online learning experience. Furthermore, results indicate that emotions were reflected in more complex interactions such as student responses in a text format found in asynchronous classroom conference postings and not in responses from students to a modified COI questionnaire/online survey measuring social presence, cognitive presence and teaching presence. The modified COI questionnaire included additional items that were designed to measure emotional presence. Using a grounded theory analysis process of open, axial and confirmatory coding, researchers found that although class conference postings and the responses in the surveys indicated that social presence was important, it appeared that more complex interactions, such as postings taking place during the submission of discussion posts in the classroom, triggered emotional states only.

The distinct effect of emotions on online learning is also evident from research investigating the performance of students during their first year of online study. The first year is a period during which social and cognitive presence is not well established, since students may not be familiar with the methodology of online learning. Zembylas (2008) showed that students experienced 
anxiety around online learning and stress and guilt surrounding their difficulties in balancing various roles and responsibilities. At the same time, they experienced joy for the flexibility of online learning, pride and contentment for completing the course requirements, and surprise regarding the emotional nature of the online communication. The experience of anxiety due to the unfamiliarity of the online methodology was higher at the beginning of the course, and it gradually decreased as the students became more familiar with the online communication. Overall, Zembyla's approach focused on formulating an account of how emotional discourse is used by the learners, its impact on learning, and how the students changed over a one year timeframe. Similarly, Conrad (2002) used a survey method to show that both female and male online students' experience of negative and positive emotions including fear, anxiety, curiosity, and excitement was evident from the beginning of an online course. However, female students reported more varied and negative emotions reflecting fear and anxiety compared with male students. Female students used more emotional adjectives to describe their experience such as being scared, intimidated, vulnerable, anxious, cautious, apprehensive, and terrified, while male students reported only feeling anxious, apprehensive, and cautious.

Frustration is a discrete emotion that appears to inhibit learning in all educational settings. Increased dropout rates and retention have been associated with increased levels of frustration in both face-to-face and online learning (Liaw, 2008). O'Regan (2003) reported that frustration was the most frequent emotion associated with online study. Frustration was mostly associated with having to work and study at the same time, a lack of clear instructions for locating the required course links, and the nature or structure of the online material. Examples for the latter include different pages having very similar layouts, difficulty reaching instructions, use of outdated course readings, and superficial nature of online discussions that were not moderated.

The development of self-regulation and self-efficacy in online learning seems to be associated with emotion, academic achievement, and the learning experience. You (2012) analyzed the responses of 535 online students and found that experiencing discrete emotions such as enjoyment fostered self-regulated learning, while negative feelings such as fear and boredom did not influence self-regulated learning. You and Kang (2014) found that enjoyment had a mediating effect on the relationship between perceived academic control and self-regulated learning, but the moderating effect of enjoyment was not significant. While anxiety and boredom did not mediate effects associated with self-regulating learning, they were significant moderators of the relationship between perceived academic control and self-regulated learning. Additionally, the relationship between perceived academic control and self-regulated learning differed significantly at different levels of anxiety and boredom. Students' experiences of a high degree of negative emotions was not associated with high academic control and self-regulated learning, suggesting that students experience of negative emotions in online courses in conjunction with the teachers' efforts seem to be necessary in order to increase students' awareness of their academic control.

\section{Emotions and types of teaching}

Although collaborative learning activities may have a positive effect on learning by developing higher level cognitive abilities such as problem solving, critical thinking, and communication abilities, there is evidence that shows that online collaborative learning may induce increased levels of frustration in students. Capdeferro and Romero (2012) conceptualized frustration as a negative emotion aroused upon encountering an obstacle in the achievement of a task, goal, or expectation, or in satisfying one's needs; frustration is thus a challenge in goal attainment. The researchers investigated computer supported collaborative learning activities (CSCL) that may interfere with students' willingness to engage in the task. The overall tasks involved collaborative writing of papers in which students had to develop a topic or solve a case study. The authors 
tested groups of four to six students that participated in online CSCL activities two to four weeks duration. The interactions of the students were based on text-based tools such as discussion forums and email. They found that not only was frustration a common feeling experienced among online students, but students' perception of unequal collaboration and commitment imbalance among group members in collaborative activities were the most significant causes of frustration.

Vuorela and Nummenmaa (2004) reported on the significant influence of emotional states on online student engagement during collaborative and individual activities. They found that students who experienced more positive emotions during an online course were less aroused than those students who experienced more negative emotions. Students experiencing positive emotions, compared with those exhibiting negative emotions, tended to participate more in collaborative activities. Shen, Wang, and Shen (2009) conducted a study that included the use of emotion detection technologies from biophysical signals and combined that data with data derived from an online e-learning platform. They reported that customizing learning material delivery on the basis of a student's emotional state improved student performance by $91 \%$. In a further analysis of data, engagement and confusion were the most important and frequently occurring emotions in learning.

These findings suggest that emotions can have a negative or a positive effect on engagement and learning. If emotions do have a direct effect on online engagement and learning, we can design courses that take into consideration the dynamic effect of emotions on the learning process. Findings also show that understanding emotions seems to be more important in online team learning involving collaborative activities than in individual learning. This is probably because the need for emotional understanding is higher when more students are involved in class discussions and collaborative activities; ultimately, their interactions provoke more complex emotional reactions.

\section{The antecedents of emotions: Cognition, behaviour, and individual differences}

\section{The control-value theory of achievement emotion}

In addition to the discrete role that emotions appear to have in student engagement in online learning, Pekrun (2006) and Pekrun et al. (2002) showed that cognitive and behavioural factors, such as self-efficacy, self-regulation, perceived academic control, and task values, function as antecedents to emotional reaction. These factors affect student engagement in the online classroom as well as academic achievement. Control value theory suggests that control and value related cognitions are antecedents of achievement emotions or emotions that are related with learning (Pekrun et al., 2002; 2010). Controlled related cognitions refer to (a) subjective appraisals of controllability of achievement-related actions and outcomes of cause and effect relations, such as self-efficacy expectations, and learning outcome expectancies, (b) causal attributions of achievement, and (c) competence appraisals. Value-related cognitions refer to appraisals that relate to the subjective importance of the respective activities and outcomes. Several studies supported the control-value theory of achievement emotion (Pekrun et al., 2002; 2010). Artino (2008a; 2008b) found that task value, self-efficacy and instructional quality were positively associated with students' satisfaction with their online studies. You (2012) also reported that task value, classroom structure, and self-efficacy were antecedents of emotional states.

\section{Behavioural antecedents of emotions}

Several theories of learning suggest that motivation is a significant factor affecting student engagement and academic achievement in traditional and online classrooms (Zimmerman, 2002; 
Yukselturk \& Bulut, 2007; You, 2012). Motivation refers to a process or an internal state of an organism that drives it to action. Most theories on motivation assert that motivational states are led by specific drives and needs. Thus, a particular behaviour is observed due to a specific motivational state; motivation is essential and a prerequisite for successful learning. External reinforcement through rewards and vicarious reinforcement (engaging behaviour for which models have been rewarded) can enhance motivation through internalization of motivational processes, self-regulation, and even self-reinforcement (Bandura, 1986).

Intrinsic motivation refers to a behaviour whose manifestation depends on internal factors such as feelings of satisfaction and fulfilment. Intrinsic motivation has been conceptualized as the most self-determined type of motivation. Researchers have examined the relationship between motivation and emotional states in online learning and showed that motivation was related to online student satisfaction with a self-paced course, while a course that minimized the control in learning provoked less satisfaction with the course among intrinsically motivated students (Cho \& Heron, 2015).

\section{Cognitive antecedents of emotions}

Self-efficacy has been shown to predict academic success (Zimmerman, 2002), and its positive effect has also been examined with in online courses. Yukselturk and Bulut (2007) found that self-efficacy, intrinsic goal orientation, cognitive strategy usage, task value, and self-regulation were positively correlated with online academic success. On the contrary, the external locus of control and educational level were negatively correlated with online success. Successful online students used self-regulated learning strategies in online courses such as self-evaluation, organization, goal setting and planning, seeking information and social assistance, keeping records, monitoring, rehearsing and memorizing. These findings are consistent with those of Greene and Miller (1996) who found that those students having intrinsic goals tended to use deeper cognitive strategies and self-regulatory strategies and were more successful than students who did not have intrinsic goals.

Task value beliefs are also linked with online students' learning satisfaction and engagement. Specifically, task value refers to an individual's beliefs about the various reasons for engaging in a task (Pintrich \& Schunk, 2002). Students' high task value beliefs contribute significantly to online students' engagement and higher order learning. Yang, Tsai, Kim, Cho, and Laffey (2006) found that online students having a perception of high task value not only used cognitive learning strategies more, but also they tended to use their peers and instructors effectively in order to enhance their learning. Lee (2011) also showed that online students having higher task value beliefs and outcome expectancies tended to be more satisfied with their learning experiences than those having lower task value beliefs and lower expectancies.

\section{Individual Differences as antecedents of emotions}

The impact of personality characteristics and emotions has been investigated less in the study of student engagement in online learning. Chen and Caropreso (2004) showed that personality affects communication type, pattern, and task engagement of students but not message length. Furthermore, students with high levels of extraversion, agreeableness and intellectual or imaginative experiences used a two-way communication and consequently participated more in collaborative online interactions. In contrast, students with high levels of introversion tended to use a one-way communication and were less able to engage in online collaborative learning. Extroverts also prefer online instruction (Daughenbaugh, Ensminger, Frederick, \& Surry, 2002). 


\section{Emotional strategies and techniques}

\section{The use of emoticons, humour, and audio in the classroom}

Aragon (2003) proposed the use of emoticons in conjunction with humour and the use of audio for creating a positive climate during online teaching. These strategies may also increase learning motivation and social presence in the online classroom. Humour should serve an instructional purpose: It should, be student-oriented, consider the instructor as the target since selfdeprecating humour does not offend others, and carefully consider how students might react especially in an online classroom whereas humour cannot be embellished by nonverbal cues (Shatz \& LoSchiavo, 2006).

The use of pedagogical humour in education can have positive effects on reducing stress levels and increasing student engagement. Although the impact of humour in education has not been studied extensively, there is evidence that shows that the appropriate and wise use of humour can assist teachers. LoSchiavo and Shatz (2005) demonstrated that the use of humour in an online psychology course affected positively student interest and participation in the course, but it did not have an effect on course performance. Further evidence for the positive influence of using humour in the online classroom comes from Kher, Molstad, and Donahue (1999), who reported that the appropriate use of humour increased students' interest and reduced their anxiety about more technical subjects such as statistics and research methods.

Emoticons can also be used for creating a more human atmosphere in the online classroom as well as making connections with students. Emoticons involve facial expressions that are created with the use of punctuation marks on the keyboard. There are recent technological advancements that allow the use of facial expressions that the learner can use that do not require the use of punctuation marks. The use of emoticons can assist the learner in interpreting the messages sent by instructors and other students, because they help convey the nonverbal messages of the communicator.

The use of audio can also assist in the creation of a positive climate in the online classroom. There are two types of audio broadcasting. During one-way audio, the instructor broadcasts to students, and in two-way audio both instructor and students broadcast to each other. The use of audio assists not only in the establishment of social presence, but also in the correct interpretation of text-based messages, since it reflects the emotions of the instructor and other students. In this way, arousal and negative emotions are minimized. The use of emoticons and two-way audio also helps in the development of a classroom community that reflects the social and cognitive presence elements and indicators of the COI model (Garrison \& Arbaugh, 2007).

\section{The use of anticipated or self-referential feedback}

The use of anticipated feedback seems to have a powerful effect on students' achievement goals and achievement emotions. Anticipated or self-referential feedback reflects students' improvement of performance over time, while anticipated normative feedback reflects the comparison between students' performance/grades. The type of achievement feedback that students anticipate to receive shapes their concept of competence and promotes the adoption of related achievement goals. In self-referential feedback, competence is defined as the improvement of a student's present performance over his/her past performance while in normative feedback competence is defined relative to other students' performance. Pekrun, Cusack, Murayama, Elliot, and Thomas (2014) showed that self-referential feedback had a positive influence on the adoption of a mastery goal, while normative feedback had a positive effect on performance approach and performance-avoidance goal adoption. Overall, the type of 
feedback and students' achievement goals predicted test-related emotions. For instance, selfreferential feedback that was based on self-improvement initiated mastery goals, while normative feedback that was based on social comparison (normative grading that leads students to perceive they performed better or worse than others) initiated performance goals. Mastery goals have been associated with students' positive affect and enjoyment of learning and were negatively linked with anger and boredom. Performance-approach goals have been associated positively with students' pride and hope while performance-avoidance goals to their anxiety, shame and hopeless. The findings suggest that mastery goals are related to activity emotions such as enjoyment, anger and boredom, while performance-based goals are related to the emotions linked to the success and failure outcomes of the activities (outcome emotions) such as hope, pride, anxiety, hopelessness, and shame.

Consequently, teachers could minimize students' experience of negative emotions and promote enjoyment in learning by helping them to master goals and engage in their learning through providing self-referential feedback. It is expected that anticipated self-referential feedback will lead students to adopt the related achievement goals, and this behaviour will help them to experience positive emotions such as enjoyment and less anger. For instance, if the student is advised to improve critical and analytical thinking, and the teacher can communicate this in terms of the students' course of improvement or non-improvement, then the student can receive a significant type of help via self-referential feedback and will be able to adopt and master the goal. The encouragement of students to employ mastery goals will also contribute significantly to students' experience of positive emotions and fewer negative emotions during online learning. Huang's (2011) meta-analysis of 77 studies $(\mathrm{N}=30,003)$ examining correlations between achievement goals and achievement emotions reported that students' adoption of mastery goals were related to more intense positive emotions while performance avoidance goals were associated with stronger negative emotions. Specifically, mastery goals were associated with positive emotions such as interest and enjoyment whistle achievement goals were associated with negative achievement emotions such as boredom and anxiety.

\section{The effect of culture on emotions}

Culture has an effect on online engagement and the experience of specific emotions. According to the universality hypothesis, all humans innately express and recognize the same emotions in nonverbal behaviours, including vocalizations (Sauter, Eisner, Ekman, \& Scott, 2010). It is widely acknowledged that language and conceptual understanding does not affect the recognition of emotions. However, there is evidence that suggests that the connections between specific vocalizations, such as crying, and specific perceived mental states, such as sadness, are not the same cross-culturally. Barrett, Mesquita, and Gendron (2011), in a review of studies on context and emotion perception, suggested that emotion perception is culturally relative and that performance is dependent on the conceptual context provided to participants (Nelson \& Russell, 2013). It is becoming clear that valence perception (the perception of a stimulus as positive or negative) rather than discrete-emotion (e.g., anger, happiness), is robust across cultures (Gendron, Roberson, van der Vyver, \& Barrett, 2014).

The relationship between emotion perception and cultural background seems to be very important in online programmes in which students and teachers from different cultures collaborate. Additionally, since verbal communication is limited in many online programmes, it is more difficult to detect emotion perception and reactions from students or teachers. Thus, the valence of emotions that is explicitly evident in verbal communication and that appears to be a universal phenomenon is more limited in online learning, making the perception of affective understanding more difficult. Consequently, the teacher and the learner need to rely on the 
emotion perception that is based on the perceptual context of the online classroom that is culturally relative; this makes cross-cultural understanding of emotions by instructors mandatory.

The effect of culture on emotions is important in all models of learning, since communication between students and teachers is so fundamental to learning. The way students from different cultures interpret different messages in different academic contexts can lead to misunderstandings and the development of negative emotions. For example, the effect of power distance, which refers to the higher status that a faculty member holds in comparison to students in many cultures, varies among cultures. For example, students from China have a high degree of power distance toward their teachers, and they may avoid approaching teachers or asking questions directly. Misunderstandings may also arise due to differences between high and low context cultures. In a high context culture, it is the listener's responsibility to figure out what is being said in a conversation, whereas in a low context culture, it is the speaker's responsibility to make sure that the message is understood. Typically, China represents a high context culture, and North American a low context culture. Students from high context cultures typically feel they have the responsibility to understand the message that it is given in an academic context, and they may avoid approaching the teacher to clarify any misunderstandings (Dimitrov, 2014). It is essential to train teachers on intercultural differences in learning to help students from different cultural backgrounds increase the chances of having a positive learning experience. Being aware of how the cultural aspects, such as students coming from high or low context cultures, influence students' behaviour, teachers can guide and support their students from such contexts and reduce students' negative emotions such as anxiety, helplessness, and frustration. For instance, if we have a student from a high context culture who quotes a lot of material from other authors in his work and avoids to evaluate the respective studies then we need to encourage our student to evaluate others' work by saying in our feedback that it 'is fine to critically evaluate others' opinions in the context of academic writing'.

\section{Creating courses with high task value}

Negative beliefs of task value are related with increased levels of frustration in the online class. Course designers and instructors can construct and provide interesting, useful and balanced learning tasks and activities in order to help students to perceive a high task value and decrease frustration. Students tend to report feelings of boredom when they perceive task demands as being challenging or not challenging. Acee et al. (2010) showed that students reported that in over-challenging situations, their feelings of boredom and other negative emotions for the task were related to anxiety. Students reported that they experienced higher levels of negative emotions such as anger, hopeless, anxiety and shame in over-challenging situations. Thus, tasks that reflect moderate challenge can reduce the potential boredom or anxiety that students may experience as a result of task demands.

\section{Cognitive strategies}

The use of learning strategies and actions to increase motivation has a direct positive effect on students' learning and academic success (Wang, Peng, Huang, Hou, \& Wang, 2008).Guidance to students can assist them in developing effective learning strategies. Clear and concise learning objectives will help students make the correct choices of and implementation of learning strategies. Increased academic control and self-regulated learning in a context of positive emotional states can also facilitate students' engagement. You, Kang, and Pahng (2013) found that perceived academic control is positively associated with self-regulated learning moderated by emotions. The study conceptualized emotions on the basis of the control-value theory of learning. Boredom and anxiety had significant moderated effects between students' perceived academic control and self-regulated learning while enjoyment did not have any significant effect. 
The use of self-reflection and correct attribution of successes and failures can help students to develop self-efficacy. The inclusion of an online questionnaire to assess student learning strategies can help as well. The Study Process Questionnaire (SPQ) (Andrews, Violato, Rabb, \& Hollingsworth, 1994) examines depth of learning and specifically how students choose to strategize their learning in a particular learning setting. Online programmes can use the SPQ in order to help students improve their learning and specifically to monitor themselves in terms of the way they study and the strategies that they use or do not use. The SPQ can increase awareness of their study and enhance their self-efficacy, since students will understand the way they study and whereas they need to be improved.

The learner's attribution for success or failure is the one that will determine self-efficacy, future expectancies, and emotion. Clear instructions and feedback to students can help students attribute their learning performance correctly. Also, instructor awareness of student understanding of the tasks can help students change attributions via positive instructor feedback or discussion. For instance, if a student believes that effort only produces success in learning, then the instructor can challenge such an attribution by offering information on the use of appropriate and effortful learning strategies that will increase learning (Linnenbrink \& Pintrich, 2002).

\section{Behavioural strategies}

Behavioural strategies involve understanding individual characteristics of students and the application of appropriate instructional interventions. Chen and Caropresso (2004) suggested that mixing introverts and extroverts in the same group created a more effective communication and task engagement. Thus, knowledge of individual differences can be used to facilitate more student engagement. Teachers can learn about their students' characteristics by inviting them to post short biographies in the classroom during the first week of the module and by asking questions about expectations from the module.

Online student engagement can also be fostered with the use of instructional interventions. The COI model emphasizes the importance of teaching presence and its categories such as design and organization, facilitation of discourse, and direct instruction. However, exact understanding of the role of teaching presence in online learning and sense of community is not clear yet (Garrison \& Arbaugh, 2007). Shea (2006) reported that only one dimension of the COI model recognition of effective directed facilitation - contributed significantly to students' sense of an online learning community. Directed facilitation, including facilitation of discourse and directed instruction, reflected two factors of the teaching presence construct. Specifically, directed facilitation was used to identify and resolve areas of agreement and disagreements with students, reinforce student contributions, and confirm understanding of content. Directed facilitation also contributed to students' increased sense of belonging to an online community of learners. Although effective instructional design and the instructors' organization contributed also to sense of the online community of learners, which included shared purpose, trust, connectedness, and learning, the collective effect on student sense of the online community was smaller.

Collaborative learning seems to be important for students' academic achievement, but as has been already suggested in this review, it is also positively associated with increased levels of frustration. Capdeferro and Romero (2012) proposed that in order to decrease frustration of online students, instructors could provide explicit information about the learning model and the collaborative activities in order to assist students in adjusting their expectations, preferences, and decision-making abilities. Additionally, in order to minimize frustration in collaborative activities, the instructor can prepare students for collaboration via instruction and development of social 
skills that are required to work in groups. Instructor presence in the classroom and instructional interaction predicted learning achievement and satisfaction more positively than social interaction between students (Kang \& Im, 2013).

\section{Collecting and analyzing students' engagement data}

Student engagement carries reputational and financial benefits as well. Consequently, student engagement data are useful in determining both quality of the academic experience and the academic success of students (Kuh, 2009). Data on engagement are essential for the measuring and monitoring continuous improvement in higher education institutions (Krause \& Coates, 2008).

Quantitative methods can include the use of the Achievement Emotions Questionnaire (Pekrun et al., 2011), a widely used and reliable instrument for assessing the learner's emotions in online classrooms or other available questionnaires, qualitative methods that can be used to understand emotions and engagement in online learning. Word clouds, which are dynamic visualizations of learners' self-reported feelings, offline interviews and purposeful online conversations, intelligent tutoring systems and avatars can also be used (Rienties \& Rivers, 2014). Offline interviews and purposeful online conversations use phenomenological interviews to study emotions and use of online peer mentoring discussions as a corpus for analysis of emotions respectively. For instance, Risquez and Sanchez-Garcia (2012) used online peer mentoring discussions as a corpus for analysis of emotion. 
Emerging Evidence Regarding the Roles of Emotional, Behavioural, and Cognitive Aspects of Student

Table 1: Emotional strategies and activities that teachers can use in order to promote students' engagement in the online classroom

Type of Strategy

Emotional

-Use of emoticons by:

- Using emoticons in the class's discussions and in the private communication with students to establish a bond with them

-Use of humor by:

- Using appropriate and judicious humor in the introduction, transitions and at the end of the unit such as photographs, illustrations and cartoons.

- Using sort, simple jokes in the introduction and transitions and using longer pieces of humor at the end of the module (Shatz and LoSchiavo, 2006)

- Deriving ideas for using humor from devoted to humor research journals such as the Journal of Polymorphous Perversity, the Annals of Improbable Research

-Use of audio broadcasting (one-way or two way)

-Provide an orientation to the module prior to the beginning of the module to reduce confusion and emotional frustration (Cho and Heron, 2015)

-Use of anticipated self-referential feedback by:

- Focusing your feedback on students' improvement or non-improvement rather on grades

- Emphasizing in your feedback to students the importance of mastery goals

-Gain knowledge of individual differences in online learning

-Construct courses and activities with high task value that reflect a balanced challenging of activities and meaningful content. The use of relevant stories or case studies is helpful in assisting students to make connections.

-Develop intercultural understanding of academic contexts, emotions and learning and reflect this understanding in your feedback and to any communication with students

-Encourage students to employ mastery goals

-Use a positive tone in your text and non-text communication with students by:

- Using norms in your communication with students such as proper greetings and closings and encouraging a classroom environment whereas a positive tone in communication prevails

- Asking from you students to use a positive tone in their communication with everyone in the classroom 
Emerging Evidence Regarding the Roles of Emotional, Behavioural, and Cognitive Aspects of Student

Engagement in the Online Classroom

Alexandra Pentaraki, Gary J. Burkholder

Table 2: Cognitive strategies and activities that teachers can use in order to promote students' engagement in the online classroom

\section{Type of Strategy}

\section{Cognitive}

-Give guidance to students to assist them to develop an effective learning strategy

-Have clear and concise learning objectives

-Assist students to predict their learned outcomes and recognize their academic control in learning by:

- Giving clear guidance and performance standards

- Providing explicit information about the learning model and the collaborative activities in order to assist students to adjust their expectations, preferences and decision-making abilities

- Utilizing motivational agents and avatars for teaching new concepts (Baylor,2012)

-Assist students to increase their self-efficacy

-Help students to become aware of their learning strategy by:

- Completing relevant scales such as the Study Process Questionnaire (SPQ) (Andrews et al., 1994) and monitor their progress

-Challenge students' attributions about learning (e.g. that effort only produces success in learning) by:

- Offering information on the use of appropriate and effortful learning strategies that will increase learning 
Table 3: Behavioural strategies and activities that teachers can use in order to promote students' engagement in the online classroom

Type of Strategy

\section{Behavioral}

-Understand individual characteristics of students by:

- Learning about their background, culture, age, previous education, work experience via asking them to post a short biography in the first week of the module

- Asking students about their expectations of the module

-Prepare students for collaboration via instruction and development of social skills required to work in a group

-Be proactive in monitoring and interviewing in collaborative activities in order to reduce students' frustration

-Structure classroom discussions

-Take an overt, directed facilitation and leadership role in the class by:

- Identifying and resolving areas of agreements and disagreements with and among students

- Reinforcing students' contributions and confirming students' understanding of the content

-Collect and analyze students' engagement data (including emotional data) by:

- Using the Achievement Emotions Questionnaire (Pekrun et al., 2011)

- Learning analytics

- Content analysis

- Natural language processing

- Behavioral indicators (e.g. the use of emoticons in online discussions)

- Word clouds

- Offline interviews

- Purposeful online conversations

- Developing empirical based student personality profiles

-Be 'present' in the class by:

- Interacting with students as much as you can

\section{Conclusions}

This review of the literature review suggests that student engagement involves discrete emotional components and antecedents of emotional reactions that have a significant impact on learning success in the online classroom. The findings suggest that discrete emotions influence selfregulated learning, intrinsic motivation, self-efficacy for collaborative learning activities, and beliefs of high task value in online learning. The effective management of negative emotions such as anxiety and frustration, and the facilitation of positive emotions such as satisfaction, are 
essential for increased engagement and academic success. Specifically, cognitive, behavioural and emotional strategies increase' engagement in online learning.

Teachers' intercultural understanding of students' emotional reactions as well as an examination of individual differences can also help increase engagement and enrolment in online learning. Institutions need to take into consideration the individual difficulties that students may experience and provide the necessary support. For instance, female students facing complex situations and responsibilities, such as balancing work and home commitments, may need more support and guidance from instructors in order to persist with their learning efforts. Collecting and analyzing engagement data via quantitative and qualitative methods can also help in assessing social, cognitive and emotional aspects of online learning.

Student engagement is a significant factor not only for traditional learning, but also for online learning as it fosters students' learning and academic achievement. There appears to be a lack of quantitative research in online learning and the community of learners with an emerging need to examine the impact of emotions on online learning and engagement. Additionally, most of the studies, including the COI model, did not examine or they did not focus their study on the relationship between cognitive, behavioural, and more recently, emotional elements that are related particularly to students' engagement. Future studies need to address the relationship between cognitive, emotional and behavioural aspects of learning and higher order thinking.

Overall, it is critical to establish the discrete effect of emotions on students' engagement and online learning. If such an effect exists, then researchers need to establish its relationship with social and cognitive presence. It is important to advance our understanding of emotional, behavioural and cognitive engagement in online learning, in conjunction with cultural and individual differences. This understanding will help online teachers to design strategies and courses that will minimize the experience of negative emotions and will enhance students' intrinsic motivation for engagement and academic success. Institutions could accelerate such an understanding via collecting data using instruments that assess emotional, cognitive, behavioural, cultural and individual characteristics.

\section{References}

1. Acee, T. W., Kim, H., Kim, H. J., Kim, J. I., Chu, H. N. R., Kim, M., \& Wicker, F. W. (2010). Academic boredom in under-and over-challenging situations. Contemporary Educational Psychology, 35(1), 17-27.

2. Andrews, J., Violato, C., Rabb, K., \& Hollingsworth, M. (1994). A validity study of Biggs' three factor model of learning approaches: A confirmatory factor analysis employing a Canadian sample. British Journal of Educational Psychology, 64, 179-185.

3. Aragon, S. R. (2003). Creating social presence in online environments. New directions for adult and continuing education, 100, 57-68.

4. Artino, A. R. (2008a). Motivational beliefs and perceptions of instructional quality: predicting satisfaction with online training. Journal of Computer Assisted Learning, 24(3), 260-270.

5. Artino, A. R. (2008b). Understanding satisfaction and continuing motivation in an online course: An extension of social cognitive, control-value theory. Paper presented at the annual meeting of the American Educational Research Association, New York, NY.

6. Bandura, A. (1986). Social foundations of thought and action. Englewood Cliffs, NJ: Prentice Hall.

7. Barrett, L. F., Mesquita, B., \& Gendron, M. (2011). Context in emotion perception. Current Directions in Psychological Science, 20, 286-290. 


\section{Emerging Evidence Regarding the Roles of Emotional, Behavioural, and Cognitive Aspects of Student \\ Engagement in the Online Classroom \\ Alexandra Pentaraki, Gary J. Burkholder}

8. Berenson, R., Boyles, G., \& Weaver, A. (2008). Emotional intelligence as a predictor of success in online learning. The International Review of Research in Open and Distributed Learning, $9(2)$.

9. Capdeferro, N., \& Romero, M. (2012). Are online learners frustrated with collaborative learning experiences? The International review of research in open and distance learning, 13(2), 26-44.

10. Chen, S. J., \& Caropreso, E. J. (2004). Influence of personality on online discussion. Journal of Interactive Online Learning, 3(2), 1-17.

11. Cho, M. H., \& Heron, M. L. (2015). Self-regulated learning: the role of motivation, emotion, and use of learning strategies in students' learning experiences in a self-paced online mathematics course. Distance Education, 36(1), 80-99.

12. Cleveland-Innes, M., \& Campbell, P. (2012). Emotional Presence, Learning, and the Online Learning Environment. The International Review of Research in Open and Distance Learning, 13(4), 269-292.

13. Conrad, D. L. (2002). Engagement, excitement, anxiety, and fear: Learners' experiences of starting an online course. American Journal of Distance Education, 16(4), 205-226.

14. Daughenbaugh, R., Ensminger, D., Frederick, L., \& Surry, D. (2002). Does personality type effect online versus in-class course satisfaction? Paper presented at the Seventh Annual Mid South Instructional Technology Conference, April 7-9, Middle Tennessee State University.

15. Dimitrov, N. (2014). Intercultural Communication and Collaboration [Video file]. Retrieved July 6, 2015 from the University of Liverpool website https://elearning.uol.ohecampus.com/webapps/portal/frameset.jsp?tab_tab_group_id=_40 _1\&url $=\% 2$ Fwebapps $\% 2$ Fblackboard $\% 2$ Fexecute $\% 2$ Flauncher $\% 3$ Ftype $\% 3$ DCourse $\% 26$ id \%3D_1509531_1\%26url\%3D

16. Fredricks, J. A., Blumenfeld, P. C., \& Paris, A. H. (2004) School Engagement: Potential of the Concept, State of the Evidence. Review of Educational Research, 74(1), 59-109.

17. Garrison, D. R., Anderson, T., \& Archer, W. (2000). Critical inquiry in a text-based environment: Computer conferencing in higher education. The Internet and Higher Education, 2, $1-19$.

18. Garrison, D. R., Anderson, T., \& Archer, W. (2010). The first decade of the community of inquiry framework: A retrospective. The Internet and Higher Education, 13(1), 5-9.

19. Garrison, D. R., \& Arbaugh, J. B. (2007). Researching the community of inquiry framework: Review, issues, and future directions. The Internet and Higher Education, 10(3), 157-172.

20. Gendron, M., Roberson, D., van der Vyver, J. M., \& Barrett, L. F. (2014). Perceptions of emotion from facial expressions are not culturally universal: Evidence from a remote culture. Emotion, 14(2), 251-262.

21. Greene, B. A., \& Miller, R. B. (1996). Influences on achievement: Goals, perceived ability, and cognitive engagement. Contemporary Educational Psychology, 21 (2), 181-192.

22. Hannon, J., \& D’Netto, B. (2007). Cultural diversity online: student engagement with learning technologies. International Journal of Educational Management, 21(5), 418-432.

23. Hu, S., \& Kuh, G.D. (2001). Being (Dis)Engaged in Educationally Purposeful Activities: The Influences of Student and Institutional Characteristics. Paper presented at the American Educational Research Association Annual Conference. Seattle, WA, 10-14 April. 
24. Huang, C. (2011). Achievement goals and achievement emotions: A meta-analysis. Educational Psychology Review, 23(3), 359-388.

25. Kang, M., \& Im, T. (2013). Factors of learner-instructor interaction which predict perceived learning outcomes in online learning environment. Journal of Computer Assisted Learning, 29(3), 292-301.

26. Kher, N. M., Molstad, S., \& Donahue, R. (1999). Using humor in the college classroom to enhance teaching effectiveness in 'dread courses'. College Student Journal, 33, 400-406.

27. Krause, K. \& Coates, H. (2008). Students' Engagement in First-Year University. Assessment and Evaluation in Higher Education, 33(5), 493-505.

28. Kuh, G .D. (2009). What Student Affairs Professionals Need to Know about Student Engagement. Journal of College Student Development, 50(6), 683-706.

29. Lee, I. S. (2011). Emotion, emotional intelligence, and e-learning. Online proceeding of the $9^{\text {th }}$ International Conference for Media in Education 2011 of KAEIM \& JAEIMS, 1-4. Retrieved June 30, 2014, from http://dasan.sejong.ac.kr/ inlee/set/set/articles/ICoME2011_K_14.pdf

30. Lee, Y., \& Choi, J. (2011). A review of online course dropout research: implications for practice and future research. Educational Technology Research and Development, 59(5), 593-618.

31. Liaw, S. (2008). Investigating students' perceived satisfaction, behavioral intention, and effectiveness of e-learning: A case study of the Blackboard system. Computers \& Education, 51, 864-873.

32. Linnenbrink, E. A., \& Pintrich, P. R. (2002). Motivation as an enabler for academic success. School Psychology Review, 31(3), 313-327.

33. LoSchiavo, F. M., \& Shatz, M. A. (2005). Enhancing online instruction with humor. Teaching of Psychology, 32, 247-250.

34. Nelson, N. L., \& Russell, J. A. (2013). Universality revisited. Emotion Review, 5, 8-15.

35. O’Regan, K. (2003). Emotion and e-learning. Journal of Asynchronous learning networks, 7(3), 7892.

36. Pekrun, R. (2000). A social-cognitive, control-value theory of achievement emotions. In J. Heckhausen (Ed.), Motivational Psychology of Human Development-Advances in Psychology. Amsterdam: Elsevier Science B.V.

37. Pekrun, R. (2006). The control-value theory of achievement emotions: Assumptions, corollaries, and implications for educational research and practice. Educational psychology review, 18(4), 315-341.

38. Pekrun, R., Cusack, A., Murayama, K., Elliot, A. J., \& Thomas, K. (2014). The power of anticipated feedback: Effects on students' achievement goals and achievement emotions. Learning and Instruction, 29, 115-124.

39. Pekrun, R., Goetz, T., Daniels, L. M., Stupnisky, R. H., \& Perry, R. P. (2010). Boredom in achievement settings: Exploring control-value antecedents and performance outcomes of a neglected emotion. Journal of Educational Psychology, 102(3), 531-549.

40. Pekrun, R., Goetz, T., Frenzel, A. C., Barchfeld, P., \& Perry, R. P. (2011). Measuring emotions in students' learning and performance: The Achievement Emotions Questionnaire (AEQ). Contemporary Educational Psychology, 36(1), 36-48. 
41. Pekrun, R., Goetz, T., Titz, W., \& Perry, R. P. (2002). Academic emotions in students' selfregulated learning and achievement: A program of qualitative and quantitative research. Educational Psychologist, 37(2), 91-105.

42. Pekrun, R., \& Stephens, E. J. (2010). Achievement emotions: A control-value approach. Social and Personality Psychology Compass, 4(4), 238-255.

43. Pintrich, P. R., \& Schunk, D. H. (2002). Motivation in education: Theory, research, and applications ( $2^{\text {nd }}$ ed.) Upper Saddle River, N.J: Merrill Prentice Hall.

44. Rienties, B., \& Rivers, B. A. Measuring and Understanding Learner Emotions: Evidence and Prospects. LACE Project - Learning Analytics Review 1. Retrieved December 10, 2014, from the http://www.laceproject.eu/publications/learning-analytics-and-emotions.pdf

45. Risquez, A., \& Sanchez-Garcia, M. (2012). The jury is still out: Psychoemotional support in peer e-mentoring for transition to university. The Internet and Higher Education, 15(3), 213-221.

46. Sauter, D. A., Eisner, F., Ekman, P., \& Scott, S. K. (2010). Crosscultural recognition of basic emotions through nonverbal emotional vocalizations. Proceedings of the National Academy of Sciences, USA, 107, 2408-2412.

47. Shatz, M. A., \& LoSchiavo, F. M. (2006). Bringing life to online instruction with humor. Radical Pedagogy, 8(2), 8.

48. Shea, P. (2006). A study of students' sense of learning community in online environments. Journal of Asynchronous Learning Networks, 10(1), 35-44.

49. Shen, L., Wang, M., \& Shen, R. (2009). Affective e-Learning: Using “Emotional” Data to Improve Learning in Pervasive Learning Environment. Educational Technology \& Society, 12(2), 176-189.

50. Trowler, V. (2010). Student engagement literature review. York: Higher Education Academy.

51. Vuorela, M., \& Nummenmaa, L. (2004). Experienced emotions, emotion regulation and student activity in a web-based learning environment. European Journal of Psychology of Education, 19(4), 423-436.

52. Wang, Y., Peng, H., Huang, R., Hou, Y., \& Wang, J. (2008). Characteristics of distance learners: research on relationships of learning motivation, learning strategy, self-efficacy, attribution and learning results. Open Learning, 23(1), 17-28.

53. Yang, C. C., Tsai, I., Kim, B., Cho, M. H., \& Laffey, J. M. (2006). Exploring the relationships between students' academic motivation and social ability in online learning environments. The Internet and Higher Education, 9(4), 277-286.

54. You, J. (2012). The structural relationship among task value, self-efficacy, goal structure, and academic emotions for promoting self-regulated learning in e-learning course. The Journal of Korean Association of Computer Education, 16(4), 61-77.

55. You, J. W., \& Kang, M. (2014). The role of academic emotions in the relationship between perceived academic control and self-regulated learning in online learning. Computers \& Education, 77, 125-133.

56. You, J., Kang, M. \& Pahng, P. (2013). Moderating Effects of Academic Emotions between Perceived Academic Control and Self-Regulated Learning in Online Courses. E-Learn, 21802188.

57. Yukselturk, E., \& Bulut, S. (2007). Predictors for student success in an online course. Journal of Educational Technology \& Society, 10(2), 71-83. 
Emerging Evidence Regarding the Roles of Emotional, Behavioural, and Cognitive Aspects of Student Engagement in the Online Classroom Alexandra Pentaraki, Gary J. Burkholder

58. Zembylas, M. (2008). Adult learners' emotions in online learning. Distance Education, 29(1), 71 87.

59. Zimmerman, B. J. (2002). Becoming a self-regulated learner: An overview. Theory into practice, 41(2), 64-70.

\section{Acknowledgements}

We are thankful to Dr. Thalia Nazario for the abstract translations in Spanish and Portuguese.

This research was supported in part by a David Wilson research grant for the study: A Comparative Analysis of Student Engagement and Higher Order Thinking in Two Approaches to the Online Classroom. Also, we would like to thank Dr Craig Marsh and Dr Laura Lynn for their kind review of the paper. 